\title{
Arte, dor e Kátharsis ou Variações sobre a arte de pintar o grito ${ }^{1}$
}

\author{
Márcio Seligmann-Silva
}

\section{Dor, terror e morte nas tradições clássica, cristã e romântica}

A relação entre arte e dor pode parecer estranha à primeira vista. A arte, segundo uma certa concepção clássica, é o campo da fruição do belo e, segundo uma certa tradição clássica ainda, a arte seria um meio de ensinar o "bem". Poder-se-ia perguntar, então, se seria possível uma conciliação entre a arte "da dor" $\mathrm{e}$ essa visão tradicional da arte? Ora, na verdade isso não só é possível, como também, de certo modo, essa modalidade da arte sempre foi no mínimo tão importante - e "clássica" quanto a sua face avessa à representação da dor.

Como é bem conhecido, na mitologia clássica podemos encontrar representadas todas as paixões, do amor ao ódio, e cenas das mais variadas tonalidades. Assim a Ilíada, uma das obras fundamentais na nossa literatura e que está na base de inúmeras obras de arte, é toda um retrato da guerra e de seus aspectos tanto heróicos quanto terrificantes. Também a tragédia grega é em muitos sentidos uma encenação da dor, em todos os seus graus, da dor física à dor pela perda, pela privação, até à dor da ferida mortal. A arte cristã também é fundamentalmente a arte da representação da paixão de Cristo; da história do seu martírio e de sua dor extrema.

Ao se falar de arte e dor devemos ter em mente esse fato. Já Aristóteles colocou no centro da sua teoria da tragédia a "purgação" das paixões eléos e phóbos, da piedade e do terror. Essa purgação só funciona graças à identificação e à conseqüente com-paixão. Sentimos terror diante da morte e tendemos a nos identificar com quem sofre: sem esse pressuposto, a tragédia e

${ }^{1}$ Uma primeira versão mais breve deste texto foi escrita em outubro de 1999 e publicada na revista Insight. Psicoterapia e Psicanálise, ano IX, n. 101, novembro 1999: 8-15. 
as representações cristãs da paixão não funcionariam. Ao assistirmos a uma tragédia de Sófocles, diante de uma tela de Grünewald (pensemos na sua crucificação de Cristo), de uma Pietá, das inúmeras representações de martírios dos santos - lembremos por agora apenas dos quadros representando São Sebastião amarrado recebendo flechas no seu corpo -, sempre "assistimos" a uma encenação da dor mediada pela identificação com aquele que sofre. Na cena da mímesis artística sempre, por assim dizer, "vivenciamos" imaginariamente a dor no nosso próprio corpo que é transmitida pela visão - e/ou pela audição, conforme a arte em questão. A arte sempre esteve relacionada à morte e ao terror a ela ligado - como encenação do sacrifício e como culto dos mortos: nos dois casos, portanto, enquanto apaziguamento e exorcismo do poder incontornável de Tânatos.

Podemos assim compreender por que a representação da dor na história da arte e da literatura é tão importante quanto as noções - complementares e não opostas a ela - de "belo" e de "harmonia". Afinal, o belo e a dor não se excluem. Por outro lado, existe uma associação possível e tradicional entre as representações da dor e a quebra na harmonia (essa quebra reforça, numa tradução "literal" do estado psíquico, a apresentação da dor), e também estabeleceu-se muitas vezes um vínculo entre a dor e o feio e, ainda, entre a dor e o sublime.

Edmund Burke, no século XVIII, foi um dos principais teóricos dessa "paixão mista" do sublime, como lemos no seu livro A philosophical enquiry into the origins of our ideas of the sublime and beautiful, publicado em 1757. Paixão mista porque nela o prazer nasce da contemplação dos limites do ser humano, vale dizer, da visão da morte não necessariamente inserida no contexto da encenação trágica ou da narrativa épica. 0 século XVIII foi também a época que deu à luz as obras de H. Füssli, com as suas representações de pesadelos, e também às de Willian Hogarth, autor da série "Os graus da crueldade"; assim como o século seguinte foi marcado pela publicação dos Desastres de la guerra e dos Caprichos de Goya - e pela obra de seu grande admirador: Baudelaire. A história da arte e da literatura sofre no século XVIII uma virada que, por um lado, rompe com a tradição poético-retórica da mímesis como imitatio, indissociável da tradição prescritiva da crítica, no mesmo momento em que funda uma compreensão estética do fenômeno artístico - e anuncia o romantismo. 
Lessing, no seu Laocoonte (1766), analisara o famoso grupo escultórico do mesmo nome tentando conciliar o seu gosto "clássico" pela arte marcada por uma determinada noção de beleza e a sua admiração por essa obra. Segundo ele, Laocoonte não grita, apenas entreabre a boca, porque, caso contrário, ele desfiguraria por demais a sua face: e a obra deixaria de ser bela. Ele propõe que tentemos imaginar o Laocoonte com a sua boca escancarada:

Era uma construção que suscitava compaixão porque mostrava ao mesmo tempo beleza e dor; agora é uma construção feia, repugnante, da qual desviamos de bom grado a nossa face, porque a visão da dor excita desprazer, sem que a beleza do objeto que sofre possa transformar esse desprazer no sentimento doce da compaixão.*

Ou seja, caso a boca estivesse escancarada no Laocoonte, a "mecânica" da arte, a saber, da sua recepção baseada na identificação, deixaria de funcionar e, ao invés da compaixão, do envolvimento do espectador, haveria lugar apenas para a repugnância ( Ekel, em alemão). 0 limite na representação da arte é, para Lessing, um limite estético a partir do qual a arte deixa de ser arte. ${ }^{*}$ A visão da dor deveria ter a contrapartida do belo, da contenção. Nesse sentido, Lessing não se afasta tanto do seu interlocutor nessa obra, ou seja, de Winckelmann, quanto ele quer parecer. Este último, como é conhecido, atribuía a contenção do grito do sacerdote troiano ao seu caráter, heróico, nobre e estóico. A diferença é que o argumento de Lessing é estético e não procede segundo a doutrina retórica do éthos.

$\mathrm{Na}$ linha da interpretação instrumental da arte como meio de ensinar ao mesmo tempo que deleita, o prodesse et delectare da retórica clássica, Hegel, nas suas Lições sobre a estética, admite a representação da dor e do martírio apenas sob o prisma da reconciliação do indivíduo com o mundo e da reafirmação tanto da subjetividade quanto do ideal:

Mesmo o Deus cristão não está subtraído à passagem pela humiIhação do sofrimento, inclusive pelo opróbrio da morte, e não é libertado da dor da alma, na qual ele deve gritar: "Meu Deus, meu Deus, por que me abandonaste?"; sua mãe sofre semelhante dor áspera e a vida humana em geral é uma vida de conflito, de lutas e de dores. Pois a grandeza e a força medem-se verdadeiramente apenas na grandeza e na força da oposição, a partir da qual o espírito consegue novamente se reconciliar na unidade em si mesmo; a intensidade e a profundidade da subjetividade se
* (Lessing, G. E. Laocoonte ou Sobre as fronteiras da poesia e da pintura. Introdução, tradução e notas de $M$. Seligmann-Silva. Colecão Biblioteca Pólen. São Paulo: lluminuras, 1998: 92.)

(Cf. Menninghaus Winfried. Ekel. Theorie und Geschichte einer starken Empfindung. Frankfurt a.M.: Suhrkamp, 1999.) 
* (Hegel. Lições sobre a estética, vol. I. São Paulo: EdUSP, 1999: 188.) distinguem tanto mais fortemente quanto mais infinita e terrivelmente as circunstâncias se encontrarem em tensão e quanto mais despedaçadoras forem as contradições, sob as quais a subjetividade, contudo, deve permanecer firme em si mesma. É apenas neste desdobramento que se confirma a potência da Idéia e do ideal, pois a potência consiste apenas em manter-se no negativo de si. ${ }^{*}$

É evidente que nem Hogarth nem Goya podem ser compreendidos à luz dessa possibilidade de reconciliação, e muito menos à luz de uma estética voltada para uma funcionalização moral da representação da dor. Esses artistas indicam um caminho pelo qual as artes enveredaram cada vez mais fundo - e que se tornou central nos cenários atuais das artes e literatura. Não é mero acaso que nesses dois artistas a representação do feio, do grotesco e da dor seja acompanhada de representações do picaresco, do carnavalesco e de outras modalidades do excesso e do riso, irônico ou não. A arte nessas obras chega à idade da sua autoconsciência: tanto de sua "materialidade" estética quanto de seu "ser artístico". Toda a "parafernália" teórica da teoria normativa ou moralizante deixa aos poucos de responder a essa nova arte. A abordagem da recepção das obras, dos seus efeitos, ganha então um lugar ainda maior, ao lado de uma reflexão sobre a sua materialidade e sobre o "papel" (função) da arte na sociedade burguesa capitalista.

Nesse processo, acelerado com o romantismo, de auto-reflexão da arte e de concomitante ascensão da importância do seu lado material, ligado à percepção, aisthesis, tanto o corpo quanto a representação da dor ganham uma nova dimensão. A arte, como que liberada das amarras do classicismo, pôde retomar o seu papel de ritual (sacrificial): de espaço de cruzamento das fronteiras e concomitante re-estabelecimento dos limites; local de teste e abalo das idéias que ajudam a manter a sociedade coesa. A arte surge como "espaço marginal" - ou seja, de apagamento/traçamento das margens - onde tanto aquilo que é posto "de lado", "para baixo", na sociedade voltada para a produtividade, pode se manifestar "livremente" , como também, ao fazê-lo, volta-se contra esse recalque que sustenta a vida social cotidiana. Daí a relação íntima entre apresentação - e não mais re-presentação - da dor (trágica) e da ironia (romântica) corrosiva e auto-reflexiva. Não por acaso a metáfora de Dioniso surgirá no meio do século XIX com Nietzsche para sintetizar, novamente, essas duas tendências. 
Também não é de surpreender, portanto, que a arte seja aproximada não só do corpo, mas das suas funções vitais, ou seja, sobretudo do sexo. Autores como o próprio Nietzsche, Hofmannsthal, Freud e Bataille perceberam e refletiram sobre esse fato. A arte como a vingança de Orfeu que havia sido despedaçado, como lemos nas Sátiras, de Horácio: eis o novo contexto das representações da dor nas artes, no qual prazer e morte, Eros e Tânatos, misturam-se. A arte torna-se - ou volta a assumir o seu papel de - rito iniciatório. Mas também - e exatamente por isso - torna-se regressiva. 0 artista que fora tratado como "gênio" no século XVIII assume agora a identidade do proto-homem; em termos tanto da espécie como também ontogenéticos. Ele representa tanto o excluído, o "outro" que está na nossa origem, pois é aquilo que marca a diferença que institui a identidade e a "normalidade" - e por isso ele encena o papel daquele que é marginalizado, do outsider-, como também ele pode ser ainda cultuado como se cultuava a arte "aurática"; pois ele encarna a nossa origem e está "além do bem e do mal", vale dizer, "além de todo valor". Ele é a origem pura, pré-diferencial do valor e dos valores. ${ }^{2}$

2 É interessante aproximar esta tentativa de esboço de topografia do "campo do estético", aberto a partir do século XVIII, onde a "arte/o artista" ocupa este lugar ao mesmo tempo central e marginal, com a reflexão schmittiana sobre a Ortung, ou localização, que orienta os limites entre o normal (normatizável pela lei) e o caos. Para Carl Schmitt, o estado de exceção é o local "atópico" e onipresente de onde o soberano comanda este traçamento de fronteiras. Ou seja, assim como na teoria política existe este espaço paradoxal, que é tanto nuclear como externo a qualquer norma e lei, a qualquer fronteira e identidade fixa, de onde emana a própria fundamentação da lei (e portanto toda lei depende da possibilidade a priori da sua violação, o soberano está aquém e além da esfera do direito), do mesmo modo o campo estético tem uma relação externa e nuclear com relação ao traçamento das identidades e valores na sociedade romântica e pós-romântica. A análise que Giorgio Agamben (cf. o seu livro Homo Sacer. 0 poder soberano e a vida nua I. Belo Horizonte: Editora da UFMG, 2002) fez dessa "estrutura de bando" (inclusão que exclui) entre a figura do soberano e a fundação da organização política leva-o a detectar a figura especular do soberano, ou seja, o homo sacer, aquele que, ao contrário do soberano, é uma espécie de sobra necessária que, por encontrar-se também banido da esfera humana e divina, é um "alimento simbólico" cobrado para manutenção da estrutura de domínio. Nesse ponto, Agamben parte de Walter Benjamin, que no ensaio "Zur Kritik der Gewalt" ("Crítica do poder/ violência") apresentou a relação umbilical entre o sistema jurídico e a injustiça, a saber, entre qualquer poder instaurado (e sua estrutura jurídica) e a violência constituinte que estava na sua origem. Onde quero chegar com essa aproximação entre reflexão política e teoria estética? Benjamin e Agamben falam de uma "vida nua" que vem à tona e é sacrificada nessa estrutura. A vida como zoé (vida natural, 
Essa "origem" é a origem do simbólico: e essa ordem simbólica nasceu de um sacrifício. Para Freud, como é sabido, esse sacrifício foi justamente o proto-assassinato, o assassinato do pai. Também Hugo von Hofmannsthal descreve, no início do século XX, a origem da poesia no sacrifício para acalmar a fúria dos deuses. Aquele que sacrifica estabelece uma troca simbólica. Nessa troca, o "outro" substitui o "próprio" e o libera da morte. Esta passa a ser apenas encenada. Desse ponto de vista, a arte é um martírio, uma passagem pela dor, pelo sofrimento e pela morte - para garantir a vida. ${ }^{3}$

\section{A arte pós-Segunda Guerra Mundial}

Esse artista Dioniso e Orfeu é, tanto quanto esses personagens, um ser no qual arte e existência não se diferenciam mais. 0 artista por excelência é o performer; nele arte e corpo são uma e a mesma coisa. Esse artista, no entanto, só pôde se desenvolver

animal) que vem à luz, afirma Agamben, e não como bios (vida em grupo). Se recordarmos a relação originária entre a arte e o sacrifício, acho que não seria ousado pensar também nas artes o mesmo movimento de vir à tona dessa vida nua - que para Agamben levou aos massacres, genocídios e à figura (biopolítica, em termos foucaultianos) do campo de concentração no século XX. No campo das artes, o vir à tona da vida nua se manifesta, creio, na arte abjeta, "do corpo"e no processo geral de dessimbolização da estrutura representativa da arte. Para esta pesquisa sobre as afinidades entre o "estético", tal como ele é pensado a partir do século XVIII e a política totalitária, cf. Lacoue-Labarthe, Philippe \& Nancy, Jean-Luc. $O$ mito nazista. (Trad. M. Seligmann-Silva. São Paulo: Iluminuras, 2002.)

${ }^{3} \mathrm{~A}$ arte como sacrifício, bem como a tentativa de erigir uma obra a partir do projeto de se pintar o grito são topoi que encontramos nas pinturas de um artista em torno do qual se mantém até hoje um verdadeiro culto e que é tido como referência central na história da arte: Caravaggio. No seu Sacrifício de Isaac, o anjo que impede Abraão de sacrificar seu filho - que grita - aponta para 0 substituto: o carneiro. 0 grito aparece também em obras como David e a cabeça de Golias, Judite e Holofernes e na Cabeça de Medusa. Louis Marin, em uma bela leitura dessas obras, analisa o cri-silencieux da Medusa como a inscrição do artista na sua própria obra enquanto aquele que petrifica e está petrificado. A Medusa teria sido representada por Caravaggio no momento em que ela se vê refletida no escudo de Perseu. 0 artista teria congelado o momento - sublime - imediatamente antes de sua morte. Arte, morte - representação do irrepresentável e grito entrelaçam-se em uma poética que não por acaso Marin atualiza e lê em pleno anos setenta do século XX. De resto, a metáfora do escudo de Perseu como uma superfície que permite que lancemos um olhar sobre o real tem sido aplicada ao cinema enquanto máquina de revelar o nosso inconsciente sem que sucumbamos diante de tais imagens. [Cf. Marin, L. "La tête de Méduse comme tableau d'histoire". Em: Détruire la peinture. Paris: Flammarion, 1997 ( ${ }^{a}$. ed. Galilée, 1977): 173-82]. 
na sua plenitude na segunda metade do século XX. Após o ritual máximo de violência da história da Humanidade - a Segunda Guerra Mundial com os seus milhões e milhões de mortos, mas também após o nazismo com a estetização paroxística do político enquanto Obra de arte total (Gesamtkunstwerk) - o artista foi mais do que nunca necessário para "aplacar a fúria dos deuses".

É evidente que a arte do pós-guerra não pode ser reduzida à performance ou às mais variadas modalidades da "arte do corpo/da dor"; é evidente também que não se deve de modo algum reduzir a arte ao nível da manifestação do retorno do recalcado. Também tem sido comum uma leitura da arte a partir de um arsenal advindo da psicanálise sem a necessária mediação com base na reflexão sobre os fenômenos da arte e da sua história. Devemos ter em mente que tanto a psicanálise como a arte possuem um desenvolvimento paralelo no século XX: e esse percurso paralelo não é nem harmônico nem epifenomênico. Mas não há dúvidas quanto ao fato de que um movimento também traduz e ilumina o outro.

A reconstrução de nossa "gramática originária" através da arte leva a arte/o artista a reencenar a proto-cisão (Urspaltung) do homem, em uma escala desconhecida na arte moderna. Proto-cisão significa aqui a construção do "eu" pela "passagem pela experiência da dor" - e da sua negação. A "arte da dor" justamente desfaz a negação/recalque da experiência dolorosa, bem como, em termos da "história da civilização", quebra os tabus que haviam sido construídos em torno do corpo e de suas excreções. Se as demais instâncias garantidoras da identidade colapsaram ao longo dos últimos duzentos anos - tais como a Religião, a Nação, o Estado, as Utopias -, deixando apenas a esfera do "ínfimo cotidiano" como último elo de ligação/identificação com o mundo, então a perda das coordenadas que garantiam uma unidade ao mundo e do sentimento de pertença daí advindo é "compensada" por esses rituais de regressão.

Sobretudo na modalidade de arte em que o corpo humano/ animal está no centro esse fenômeno é evidente. Nessa arte que quer "redesenhar" o homem, é preciso primeiro apagar os limites dos conceitos e das polaridades que sustentavam a sua identidade: daí advém uma série de ambigüidades típicas dessa modalidade de arte. Para Freud, a "dor, em si e para si, engloba a possibilidade do sentimento de prazer": em outros termos, 
(Foster, Hal. "Der Kult der Abjektion". Em: Neue Gesellschaft für Bildende Kunst (org.). Gewalt / Ges chäfte. Eine Ausstellung zum Topos der Gewalt in der gegenwärtigen künstlerichen Auseinandersetzung. Berlin: NGBK, 1995: 92-3. pulsão sexual e crueldade sempre andaram juntas desde as nossas "origens". A "arte do corpo" tenta reinscrever o simbólico: apagar/retraçar os limites entre o homem e a natureza. Devemos atentar também para o fato de que, na medida em que 0 homem avança no domínio dos códigos da natureza, paradoxalmente esta parece se diferenciar cada vez menos enquanto uma instância destacável da "cultura". 0 artista é, portanto, aquele que, hoje, leva mais adiante as visões do homem-animal e também do homem-máquina.

Podemos afirmar com certa segurança que a tendência ao emprego do corpo como "suporte"/tema da arte não será logo superada; muito pelo contrário. A arte do corpo - dos seus limites e do corte (literal, como em algumas obras de Gina Pane e dos performers de Viena dos anos 1960 e 1970 Günter Brus, Otto Muehl, Hermann Nitsch e Rudolf Schwarzkogler ${ }^{4}$ ) desses limites, arte do abjeto, como Kristeva a denominou, das excreções, daquilo que desestrutura a ordem, a identidade e os significados controlados/controladores - é uma arte que ao mesmo tempo é fruto da violência da técnica e a desafia (como nas obras do casal performer sadomasoquista Bob Flanagan e Sheree Rose): nela muitas vezes arte e técnica se unificam, mas de um modo bem diferente do que ocorria na tecné da antigüidade. Agora não se trata de produção de algo, de mímesis, mas sim de uma manifestação da arte como "interiorização do sacrifício", como Adorno e Horkheimer o definiram. Essa arte é filha de uma "cultura da pulsão de morte" - e do culto dessa pulsão, como afirma por sua vez Hal Foster.*

0 performer australiano Stelarc representa um exemplo conhecido nesse sentido. Suas máquinas funcionam como extensões da pele, este que é nosso maior órgão e dos mais "esqueci-

\footnotetext{
${ }^{4}$ Vale a pena notar que as ações desses artistas performers autodestrutivos têm muito de mise en scène e estão rodeadas de mitologias e lendas que a crítica de arte alimenta generosamente. Para um interessante levantamento da construção desses mitos de auto-emasculação e de suicídio em performances (ação atribuída por muitos autores até hoje a Rudolf Schwarzkogler), cf. Drühl, Sven. "Düstere Legenden. Vom Mythos des Suizids und der Autoamputation der Aktionkunst". ( Kunstforum, vol. 153, jan./mar.2001:74-82. Nesse mesmo volume há um dossiê muito informativo sobre arte e violência, "Choreografie der Gewalt", p. 44-229.) É evidente que a encenação muitas vezes enganosa das amputações em público ganha importância justamente pela recepção ávida e acrítica dos espectadores, especializados ou não. Há uma óbvia complementaridade entre os dois movimentos, do público e dos artistas.
} 
dos", apesar e devido à sua supervisibilidade. É este tecido que traça nossos limites que é antes de tudo posto à prova pela body art. É interessante notar o percurso de Stelarc. Ele vai da exploração das entranhas com seus filmes sobre seus pulmões, estômago e intestino - rompendo de modo explícito o tabu que estava na origem da reflexão estética do século XVIII, voltaremos a esse ponto ao tratar de Serrano -, passa pelas suas 25 suspensões de seu próprio corpo nu, elevado no ar apenas por enormes anzóis enfiados em sua pele e atados a fios amarrados no teto da galeria de arte, até às ações com máquinas que prolongam a pele e permitem uma "conversa tátil" à distância que muitas vezes dispensa a imagem do parceiro; verdadeira anulação da fotografia enquanto meio radicalmente visual e entronização do tato, o sentido mais matérico/concreto e visto desde o Renascimento como o menos preciso. ${ }^{5}$

Já uma artista como Cindy Sherman - ou mesmo Nan Goldin - dá mostras dessa nova modalidade da arte, por um lado como exercício de desconstrução da representação - tanto no seu sentido de representação ilusionista (e nesse sentido ela é continuadora das Vanguardas), como também das diversas representações dos papéis atribuídos às mulheres -, por outro ela apresenta uma arte nascida de uma cultura onde a identidade se tornou uma vestimenta que pode ser trocada conforme a

${ }^{5}$ Para uma esclarecedora história da pele, de suas metáforas e usos, cf. Benthien, Claudia. Haut. Literaturgeschichte - Körperbilder - Grenzdiskurse. (Reinbeck bei Hamburg: Rowohlt, 1999.) Paralelo às impressionantes transformações na Biologia e, mais especificamente, na Genética, existe um verdadeiro boom nos últimos anos de obras, exposições e catálogos sobre a questão do corpo - e da violência. A ligação entre um tema e outro é tópica. Eu lembraria aqui da exposição e do catálogo Abject Art do Whitney Museum (New York, 1993) e da exposição ocorrida em 1995 em Berlim que originou o catálogo Gewalt/ Geschäfte. Eine Ausstellung zum Topos der Gewalt in der gegenwärtigen künstlerichen Auseinandersetzung. Uma das mais importantes exposições sobre a história da representação do corpo ocorreu na Hayward Gallery de Londres em 2000/2001, "Spetacular Bodies" (cf. Kemp, Martin \& Wallace, Marina. Spetacular bodies. The art and science of the human body from Leonardo to now. Berkeley / Los Angeles / London: University of California Press, 2000). Na Alemanha, a recente exposição do médico Gunther von Hagens "Körperwelten", que apresenta com estrondoso sucesso a sua coleção de "esculturas" feitas com cadáveres humanos e conservada por um método de plastination por ele desenvolvido, é também uma mostra eloqüente da atração mórbida da nossa sociedade e da nossa "crise do corpo", "da vida" ou "do real". Vale lembrar o subtítulo desta exposição:"Die Faszination des Echten", "a fascinação do autêntico". Uma dessas "esculturas" segura na mão a sua própria pele, com altivez, como na tradição dos tratados de anatomia desde o século XVI. 
(Cf. Benjamin, W. "Experiência e pobreza". Em: Obras escolhidas l: Magia e técnica, arte e política. Trad. S. P. Rouanet. São Paulo: Brasiliense, 1985.)

(Cf. Dubois, Philippe. ato fotográfico. $2^{\mathrm{a}}$ ed. Campinas: Papirus, 1998.) ocasião, como uma roupa (ou como uma pele, como no caso da artista francesa performática Orlan, cuja obra consiste em mudar periodicamente a sua face por meio de operações plásticas). Essas artistas não tanto comemoram essa "nova barbárie" pósmoderna e a liberdade que a acompanha - que Benjamin já detectara* -, mas sobretudo expõem o trauma, a dor dessa nova situação. Qual a modalidade dessa encenação? Pura mise en scène neo-romântica? Isso pouco importa, e seria um moralismo barato condenar essa arte por tal viés. A própria Nan Goldin está consciente dos limites da noção da self-destruction as glamorous que estava na base de seu livro The ballad of sexual dependency, de 1986, assim como Cindy Sherman se diverte com a sua apropriação da estética dos filmes de terror " $B$ " que marca as suas obras desde o fim dos anos oitenta.

Essa arte "do corpo" não pode, portanto, ser limitada à superfície da nossa pele (e aos seus excrementos): existe uma arte do amorfo que se multiplica por inúmeros suportes. A fotografia e a Land art são dois exemplos dessa arte, sendo que a primeira no contexto da análise da arte-dor é essencial, como as obras de Sherman e Goldin o testemunham.

\section{0 olhar sobre o real}

Um aspecto central dessa arte é a sua recepção. Se o voyeurismo é uma das marcas da relação com o pré-simbólico - com o "real" enquanto essa esfera do que escapa ao simbólico -, ele também não deixa de ser essencial tanto na nossa sociedade colonizada pelas imagens como nas suas manifestações artísticas. Assim como Andy Warhol tomou a radicalização do princípio da reprodução ad nauseam das imagens como um dos princípios da sua arte - sendo que a sua série sobre a violência e a morte na América expõe o que restou da "civilização" industrial na era da Guerra Fria: a repetição melancólica do trauma -, Richard Prince, por sua vez, trabalha com o glamour de uma sociedade dominada pelas fotos publicitárias. A repetição das imagens não apenas destrói a unicidade e a tradição - a "aura" das obras -, mas também dessimboliza as imagens: estas regridem a um estágio pré-simbólico.

Nan Goldin registra com a sua câmara não apenas a esfera do seu ínfimo cotidiano bas-fond-tentando assim criar a "sua família" via álbum de fotografias -, mas também seus amigos doentes soropositivos, sendo que as fotos tornam-se atos e gestos 
de despedida. A foto funciona aqui em diferentes níveis: como arte da memória, que é acompanhada, paradoxalmente, de uma afirmação da perda da tridimensionalidade da cultura (ou seja, da sua densidade histórica) e também como arte antimimética. A foto funciona no registro indexal (como índice) como uma cicatriz, ruína, traço de algo com o qual ela mantém uma conexão física. Ela testemunha algo: via de regra doloroso. Como nos fotogramas de László Moholy-Nagy, também na arte do trauma as coisas deixam um traço - uma sombra - na superfície da memória que é queimada pela luz dos "acontecimentos"; daí a fotografia ser uma espécie de suma dessa modalidade de arte da memória.*

0 observador, diante dessas "imagens da dor/do trauma", sente justamente a repugnância mencionada na passagem de Lessing acima citada. Mas nós já nos despedimos há tempos da arte ilusionista: agora a arte abjeta quer nos confrontar com uma imagem diante da qual muitas vezes nossa mente - como na contemplação do sublime - não pode mais pensar; nós como que "nos perdemos" diante dessas imagens. Como achar um conceito para as imagens, por exemplo, de The Morgue, de Andres Serrano? Essa arte abjeta embota a reflexão. Podemos considerar que esse embotamento também pode significar uma pausa necessária, imposta pela arte. Por outro lado, essa espetacularização da dor leva não mais à uma improvável kátharsis com a sua participação identifictória (méthexis), mas dá-se na chave de um olhar que foi educado pela perspectiva estética, elaborada a partir do século XVIII e que culmina agora com o avesso da identificação piedosa, ou seja, com a pura dessubjetificação sem o momento de fusão ecstasica. Aqui, a kátharsis só pode ser pensada enquanto fusão regressiva com o proto-eu pré-simbólico.

Susan Buck Morss tentou explicar essa arte abjeta a partir do conceito benjaminiano de choque: a onipresença do choque e da violência imposta pela tecnologia na modernidade teria essas obras como seu "resultado". Talvez a noção benjaminiana de "inconsciente ótico" também nos auxilie nesse contexto: essas fotos seriam a manifestação de uma camada oculta da nossa economia psíquica que se manifesta em uma cultura abalada pela violência e que procura a todo momento retraçar as suas fronteiras.

Confrontado com os poemas de Paul Celan, Adorno, na terceira parte de sua Dialética negativa, escreveu que "a dor
(Cf. Seligmann-Silva, M "Do delicioso horror sublime ao abjeto e à escritura do corpo". Em: Andrade, A. L.; Camargo, M. L. de Barros \& Antelo, R. (org.). Leituras do ciclo. Florianópolis: ABRALIC, 1999: 123-36.) 
(Adorno, Th. W. "Negative dialektik". Em: Gesammelte Schriften, vol. 6. Frankfurt/ M.: Suhrkamp, 1975: 355 Cf. também as digressões de Adorno sobre esse em suas anotacões de curso de 1965: Metaphysik: Begriff und Probleme. Em: Nachgelassene Schriften, seção IV, vol. 14. Frankfurt/M: Suhrkamp, 1998: 172-ss.)

(Sylvester, David. Inter views with Francis Bacon. Oxford: Thames and Hudson, 1993.) perene tem tanto direito à expressão, como o torturado ao grito; por isso pode ter sido errado afirmar que não se pode escrever mais nenhum poema após Auschwitz" ${ }^{\prime *}$. 0 "grito" da poesia de Celan não é de modo algum um grito como o de Filoctetes de Sófocles - como Winckelmann afirmou comparando-o ao Laocoonte -, mas sim uma voz mais "contida" ou, melhor dizendo, mais "quebrada", fragmentada, vale dizer: sufocada. Nesse poeta, a arte da memória - da dor e do trauma - não pode de modo algum ser resumida ao acting out que marca muitas das obras contemporâneas (sem que com isso eu queira dizer que essas obras devam ser reduzidas a um "sintoma", ou mesmo que elas sejam "inferiores"). Sem "trair" o passado - sem abandoná-lo a uma impossível perlaboração/tradução total ou a um entendimento (pseudo)totalizante que significaria o mesmo que esquecer -, ele enfrenta a difícil tarefa de dar forma ao sem-forma, que, no seu caso, de modo bem específico, tem um nome: Auschwitz. A arte de Celan - diferentemente da arte para Lessing - possui um limite muito mais determinado pela ética (da memória) que pelo estético.

Também um artista como Francis Bacon tem uma obra que em boa parte pode ser vista como uma série de variações sobre o grito. Na sua famosa entrevista a David Sylvester, ele volta diversas vezes a esse tema. ${ }^{*}$ É importante notar que ele se diz mais obcecado pelo grito "em $\mathrm{si}^{\prime \prime}$, pela sua pureza material e visual, e não tanto pelo horror que ele exprime (sendo que essa preocupação com a expressão estaria presente tanto na retórica plástica do Laocoonte como no famoso 0 Grito de Munch, de 1893). Ele quer captar o movimento do grito "e a forma da boca e o dente" [and the shape of the mouth and the teeth]. 0 que importa para Bacon é "a cintilação e a cor que vem da boca" [the glitter and colour that comes from the mouth]. Ele afirma ainda que gostaria de ter pintado uma boca, "como Monet pintou um pôr-do-sol". Essa preocupação com a cintilação da boca que o atraía e essa busca de uma representação que des-significasse o grito, transformando-o em um evento estético, são momentos característicos da arte do trauma que vimos acima. Bacon é um dos artistas que, antes de Cindy Sherman, melhor registrou a tendência da arte contemporânea para esse apagar e retraçar incessantes dos limites do "eu". Suas representações de pessoas gritando, de carniças, de atos sexuais, de faces deformadas e de pessoas "posando" (ou re-presentando 
pessoas que posam) são muitas vezes "enquadradas" por formas cúbicas ou círculos que reduplicam o espaço emoldurado da tela: que retraçam o campo do limite e do ilimitado, tanto do "eu" como da "cena do estético". As imagens "violentas" são expostas para o prazer voyeurista dos espectadores. "A encenação desse "eu" que se desmancha é realizada na verdade sobre uma espécie de palco, o que não apenas acentua o tom "cênico" dos quadros, distanciando o observador, como também esse distanciamento permite um voyeurismo mais reflexivo da violência (diferentemente, portanto, do que ocorre com a série de Andres Serrano mencionada acima ou na body art). 0 fato de Bacon estar preocupado com o movimento, com a materialidade do grito, é trabalhado tanto na forma do tríptico - na apresentação de três cenas, que na verdade desconstroem os três momentos arquetípicos passado, presente e futuro congelando-os em um agora estático - como também na sua tinta acrílica e nas suas cores fortes e contrastantes. A violência e a dor que emanam dessas obras são tão encenadas que se torna impossível qualquer forma de identificação imediata. Aqui também o espetáculo da dor e da violência é um espetáculo do estético e do eu reduzido a uma "autoperformance" desestruturadora/estruturadora de si mesmo.

No caso extremo de Serrano, na sua série The Morgue mas também de muitas outras obras (fotográficas) suas, não se trata tanto da representação da dor, mas sim da apresentação da morte e sobretudo do cadáver, daquilo que sempre se deixa de fora, que "cai" (cadáver, assim como o verbo esquecer, vem do latim cadere, cair) como algo ob-sceno que, de algum modo, atrai, e por isso mesmo deve ser obscurecido, ocultado. Mas nessa série - como nas obras do casal Flanagan e Rose (essas, sim, espetáculos da dor) - o próprio espectador é "violentado", traumatizado. Não ocorre aqui o movimento reflexivo de apresentação reiterada da cena da representação artística, como em Bacon. A fotografia revela de modo mais direto o "inconsciente ótico". É interessante notar que em The Morgue as imagens que menos chocam são também as menos estetizadas - como em Pneumonie due to drowning e em Multiple stabbing. Nessa última, o elemento terrífico que acompanha a contemplação das demais obras é atenuado pela visão do sangue e da sujeira, que tem o efeito de "humanizar" a morte. Serrano também possui obras sobre temas cristãos, como Pieta e Crucifixion,
(Cf. Menke, Christoph. "Der ästhetische Blick: Affekt und Gewalt, Lust und Katharsis". Em Koch, Gertrud (org.). Auge und Affekt, Wahrnehmung und Interaktion. Frankfurt/M.: Fischer, 1995: 230-46.) 
(Cf. Seligmann-Silva, M. "Do delicioso horror sublime ao abjeto e à escritura do corpo". Op. cit.)

[Cf. Chéroux, Clément (org.). Mémoire des camps. Photographies des camps de concentration et d'extermination nazis (1933 1999). Paris: Marval, 2001.] nas quais ele trabalha imagens sacras com urina e com certas técnicas que paradoxalmente atingem o efeito de sfumato de Leonardo e da escola veneziana. Assim ele - ironicamente! re-auratiza as suas obras. Aura e urina: com fórmulas como esta Serrano quer não só chocar ou empregar técnicas aprendidas na publicidade (cf. as fotografias de Oliviero Toscani para Luciano Benetton). Ocorre também nas suas obras uma encenação do corpo/do artista, como campos específicos para dramatização da dor e da paixão. A arte de Serrano, ao querer estetizar a visão da morte, caminha no sentido de uma superestetização que culmina, no limite, em uma antiestética: percepção (aisthesis) em demasia transforma-se em impossibilidade de percepção. Cegamento, como na arte sublime, mas pela via do abjeto: do cadáver que nos puxa para baixo, e não do sublime, que nos "eleva". * A arte quer mostrar o i-limitado, sem medo da "queimadura" que a visão do "real" implica. Este "corte" na fina película do "real" representa na verdade um momento no processo de dissolução das fronteiras que é característico do que se convencionou denominar de pós-modernidade. Diferentemente de um Celan, Serrano não se defronta com a questão da ética do limite: ou se defronta com ela apenas de uma forma negativa, apagando todos os limites e a possibilidade de uma reflexão sobre a ética (que é sempre uma reflexão sobre o limite e o respeito ao outro). 0 fundamentalismo estético de Serrano bloqueia a passagem para o ético e leva, paradoxalmente, à desmontagem (e recriação) do estético. Ele des-significa e des-realiza o cadáver e a morte via sua estetização; por outro lado, diferentemente de Bacon, que busca um paroxismo do olhar estético, suas obras tendencialmente bloqueiam a relação de apreciação estética. 0 olhar fica cegado e dominado pelo movimentoreflexo do asco. 0 mesmo ocorre, de resto, nas fotos que documentam catástrofes extremas no avesso deste registro paroxístico do estético, como os cadáveres nos campos de concentração nazistas ou em certas descrições de pessoas torturadas. ${ }^{6}$ *

"O tema da "descrição" constitui um capítulo à parte na teoria da representação/apresentação da dor e da violência e, infelizmente, não posso entrar nele aqui. Lessing e Goethe, apesar de não concordarem totalmente com respeito a essa questão, expressaram idéias interessantes sobre esse tema. Quanto às descrições de pessoas torturadas, uma das passagens mais violentas que conheço encontra-se no relato de Rigoberta Menchú das torturas sofridas por seu irmão e sobretudo da - polêmica - cena em que seu irmão foi queimado pelos militares 
Nada mais distante, por exemplo, da estética eminentemente marcada pela ética da representação de um Claude Lanzmann*, que seguiu no seu filme Shoah o tabu da proibição das imagens dos cadáveres justamente para evitar a des-significação da Shoah. Se Lanzmann, no cinema, Celan, na poesia, e Anselm Kiefer ${ }^{*}$, nas artes plásticas, trabalham na delicada e tensa linha de demarcação entre o abjeto e o sublime, Serrano, por sua vez, tenta estabelecer uma conexão implausível entre o abjeto e o aurático (marcado pelo domínio do "valor de culto").

Kristeva* sugere que a arte abjeta possui uma função catártica. Talvez ela tenha razão, mas essa catarse não é a mesma teorizada por Aristóteles, mas sim apenas uma versão simplificada da mesma, que vê na arte uma válvula de escape e um balanço compensatório dos recalques cobrados pela cultura. Mas devemos ter em mente que a arte atual passa pela reflexão - como no caso tanto dos artistas que trabalham dentro de uma "ética da representação", como também na linha do olhar estético que marca as obras de um Bacon -, como também passa por uma recepção pós-estética, como em Serrano e outros artistas do abjeto. As obras destes últimos não podem ser pensadas dentro de uma ética da pólis (ou da política da representação, no seu sentido também da representação política), pois estão além e aquém da questão do contexto e, portanto, não levam em conta o histórico. ${ }^{7}$

da ditadura em praça pública junto com um grupo de prisioneiros. Apesar do texto de Rigoberta ser uma transcrição feita por Elisabeth Burgos, o fato de ele ser narrado em primeira pessoa por um personagem político de destaque e que desperta nossa identificação traz uma dimensão e um peso que a ficção não pode atingir. Se nos recordarmos que Lévinas, em 1962, escreveu sobre o Yossel Rakover de Zwi Kolitz - uma obra que então ainda era considerada pela maioria de seus leitores como sendo um documento testemunhal autêntico -, que aquele texto era "verdadeiro como apenas a ficção pode o ser", podemos pensar no efeito de desrealização que a descrição "em primeira mão" de uma tal cena pode criar. A verdade é, no entanto, que ela não cria necessariamente este efeito. Afinal, não existe "grau zero" do testemunho e não existe meio de se delimitar onde o "literário" (e também o "ficcional") começa. Cf. Lévinas, Emmanuel. "Aimer la Thora plus que Dieu". (Em: Kolitz, Zvi. Yossel Rakover s'adresse à Dieu. Paris: Calmann-Lévy, 1998: 101-11.)

${ }^{7}$ A questão de fundo - e essencial - aqui é se essa arte não significa um desdobramento da estetização do político. A recusa da ética e da política da representação também é um fato político. Por outro lado, deve ficar claro que não cabe à crítica ou à reflexão sobre a arte de um modo geral estabelecer um tabu com relação às diversas modalidades de arte. 0 papel desses metadiscursos é refletir sobre as "origens" e conseqüências - estéticas, éticas e políticas - dessas manifestações.
(Cf. Felman, Shoshana. "Educação em crise, ou as vicissitudes do ensino". Em: Seligmann-Silva, M. \& Nestrovski, A. (org.) Catástrofe e representação. São Paulo: Escuta, 2000: 13 71 e Pelbart, Peter Pál. "Cinema e holocausto". Em: Seligmann-Silva, M. \& Nestrovski, A. (org.) Catástrofe e representação. Op. cit. 171-83.)

(Cf. Salzman, Lisa. Anselm Kiefer and Art After Auschwitz. Cambridge: Cambridge UP, 1999.)

(Kristeva, Julia. Pouvoirs de l'horreur. Essai sur l'Abjection. Paris: Gallimard, 1980.) 
Evidentemente, se quiséssemos discutir todos os aspectos da questão arte e dor/violência, deveríamos analisar ainda a função dessa arte em um registro que não o do âmbito muito restrito das Bienais e exposições de arte. Mas esse não foi o meu objetivo aqui. A arte contemporânea, no entanto, apesar de ter conquistado uma esfera da liberdade estética oposta ao programa da educação estética da humanidade de um Schiller, representa uma esfera onde os principais problemas da contemporaneidade estão sendo refletidos e retrabalhados de uma modo ao mesmo tempo vertiginoso e criativo. Se, para Schelling, o artista era o mediador do Universal, hoje em dia tendemos a ver na sua arte a manifestação de um "real" que assombra a nossa sociedade supertecnológica. Essa arte decerto não pretende dar "respostas" aos nossos atuais dilemas. Mas cabe a nós dialogar com a "arte da dor", que pode nos mostrar não apenas como pensar as fraturas das nossas identidades, mas também pode justamente nos ensinar a não esperar respostas completas e prontas para os desafios impostos pelo convívio em uma sociedade agredida pelas violências tecnológica, urbana e social e acuada pela questão da diferença e pelas duas vertentes mais irracionais da "solução" dessa questão: a da globalização - que nega as diferenças - e a do fundamentalismo que reafirma a velha ontologia racista. 0 campo do estético não pode mais ser pensado como independente do ético. 
Márcio Seligmann-Silva

Doutor em Teoria Literária e Literatura Comparada pela Universidade Livre de Berlim. Autor do volume Ler o livro do mundo. Walter Benjamin: romantismo e crítica poética (São Paulo: Iluminuras, 1999) e Adorno (São Paulo: Publifolha, 2003), organizador dos livros Leituras de Walter Benjamin (São Paulo: AnnaBlume, 1999) e História, memória, literatura. O testemunho na era das catástrofes (São Paulo: Ed.UNICAMP/ FAPESP, 2003) e co-organizador do livro Catástrofe e representação (São Paulo: Escuta, 2000). Traduziu, entre outros livros, de W. Benjamin 0 conceito de crítica de arte no romantismo alemão (São Paulo: Iluminuras, 1993), e de G. E. Lessing Laocoonte. Ou sobre as fronteiras da poesia e da pintura (São Paulo: Iluminuras, 1998). É professor de Teoria Literária e Literatura Comparada no Instituto de Estudos da Linguagem da UNICAMP.

\section{Resumo}

0 autor analisa a relação entre a arte e a representação da dor partindo de uma tese central: a arte desde o romantismo tendeu cada vez mais para a apresentação do "real" enquanto aquilo que escapa ao simbólico. A arte vincula-se cada vez mais a uma apresentação (e não mais à representação) do momento violento constitutivo do ser humano. Na contemporaneidade, 0 autor detecta três modalidades dessa arte de apresentar a dor: a que parte de uma abordagem ética da memória (como em Anselm Kiefer e Claude Lanzmann), a que radicaliza o olhar estético inaugurado no século XVIII (como em Francis Bacon) e a que leva às últimas conseqüências a noção de arte abjeta (como em Andres Serrano). 0 autor destaca ainda a importância dos conceitos de sublime e de escritura (indexical) do corpo para se compreender essa nova modalidade da arte da dor, bem como a sua relação estrutural com a fotografia.

\section{Abstract}

The present paper analyses the existing relations between art and representation of pain, taking as central thesis the idea that, since romanticism, art has increasingly tended to a presentation of the "real", understood as that what escapes our power to symbolise. Art bonds itself more and more to presentation (instead of representation) of the constitutive violent moment

\section{Résumé}

L'auteur analyse le rapport entre l'art et la représentation de la douleur à partir d'une thèse centrale: depuis le romantisme l'art tend de plus en plus vers la présentation du "réel » comme quelque chose qui échappe au symbolique. L'art se lie toujours plus à une présentation (et non à la représentation) des moments violents qui constituent l'être humain. L'auteur détecte trois

\author{
Palavras-chave \\ abjeto \\ arte do corpo \\ ética e arte \\ limites da representação \\ sublime \\ Keywords \\ abject \\ art and ethics \\ body art \\ limits of representation \\ sublime
}


Recebido em of human being. Throughout the article, the author describes three modalities of the art of presenting pain in contemporary culture: one that draws from an ethic approach of memory (as in Anselm Kiefer and Claude Lanzmann), one that radicalises the aesthetic gaze inaugurated in the Eighteenth century (as Francis Bacon), and one that takes abject art to its ultimate consequences (as does Andres Serrano). The author also point out the importance of concepts such as the sublime and (indexal) body writing to understand this new modality of the art of pain, as well as its structural relation to photography. modalités dont I'art se sert pour présenter la douleur dans le monde contemporain : celle qui part d'une approche éthique de la mémoire (comme chez Anselm Kiefer et Claude Lanzmann), celle qui radicalise le regard esthétique inauguré au XVIIIe. siècle (comme chez Francis Bacon) et celle qui porte la notion de I'art abjecte à ses dernières conséquences (comme chez Andres Serrano). L'auteur met encore en relief I'importance des concepts de sublime et d'écriture (indexée) du corps pour que l'on puisse comprendre cette nouvelle modalité de l'art de la douleur aussi bien que son rapport structural à la photographie. 